\title{
Yaşlanma ile İlişkili Vitreus Humor Değişikliklerinin Difüzyon MRG ile Değerlendirilmesi
}

\author{
Evaluation of Vitreous Humor Changes Associated with Aging by Diffusion MRI
}

\section{Ali Küpeli ${ }^{1}$, Mehmet Koçak ${ }^{1}$, Gürkan Danışan ${ }^{2}$, Mehmet Soytürk ${ }^{1}$}

${ }^{1}$ Erzincan Binali Yıldırım Üniversitesi, Mengücekgazi Eğitim ve Araştırma Hastanesi, Radyoloji Anabilim dal, Erzincan, Türkiye

${ }^{2}$ Muş Devlet Hastanesi, Radyoloji Bölümü, Muş, Türkiye

\author{
Yazıșma Adresi / Correspondence: \\ Ali Küpeli \\ Erzincan Binali Yıldırım Üniversitesi, Mengücekgazi Eğitim ve Araştırma Hastanesi, Radyoloji Anabilim dalı, 24100, Erzincan, Türkiye \\ T: +90446212 2213 E-mail: : dr.ali_3383@hotmail.com
}

Geliş Tarihi / Received : 26.02.2019 Kabul Tarihi / Accepted : 15.05.2019

Orcid:

Ali Küpeli https://orcid.org 0000-0002-5322-2972

Mehmet Koçak https://orcid.org 0000-0003-3590-0327

Gürkan Danışan https://orcid.org 0000-0003-2052-0006

Mehmet Soytürk https://orcid.org 0000-0002-9011-3660

\footnotetext{
Öz

Amaç BBu çalışmada, vitreus humorde yaşlanma ile ilişkili oluşan değişiklikleri difüzyon ağırlıklı görüntüleme (DAG) ile belirlemeyi amaçladık. ( Sakarya Tip Dergisi 2019, 9(2):266-271 )

Gereç ve Ekim 2018 ile Ocak 2019 tarihleri arasında, veri tabanımızda anahtar kelime arama özelliği ile beyin DAG tetkiki uygulanan hastalar retrospektif olarak tarandı ve vitreus Yöntemler kanaması, glokom, kontrolsüz hipertansiyon veya diabetes mellitusu olan hastalar çalışma dışında bırakıldı. Sonuçta, 211 hasta çalışmaya dahil edildi ve hastalar yașlarına göre dekadlara ayrıldı. Yaşın, vitreus humor görünür difüzyon katsayısı (ADC) değerlerine etkisi regresyon analizi ile değerlendirildi.

Bulgular Çalışmaya dahil edilen 211 hastanın (102 kadın, 109 erkek) yaşlarının ortalaması 53,8 ( $\pm 21,4)$ yıl olup en az 3 yıl ve en fazla 89 yıldır. Vitreus humor ADC değerleri artan yaș ile birlikte lineer artış gösterdi ve istatistiksel olarak anlamlı pozitif korelasyon saptandı $(\mathrm{p}<0,001)$. Dekadlar arasındaki vitreus humor ADC değerleri karşılaștırıldığında ilk üç dekad arasında anlamlı fark saptanmazken $(\mathrm{p}>0,005)$ diğer dekadlar arasında istatiksel anlamlı fark saptandı $(\mathrm{p}<0,005)$.

Sonuç Vitreus humorde yaşlanma ile ilișkili yapısal değișikliklerin anlașılması daha etkili tedavi geliștirmek için önemlidir. Çalıșmamızın sonuçlarına göre, vitreus humor ADC değerleri ilk üç dekadda anlamlı fark göstermemekle beraber artan yaşla beraber pozitif korelasyon gösterdi.

Anahtar göz; difüzyon ağırlıklı görüntüleme; vitreus humor

Kelimeler

Abstract

Objective In this study, we aimed to determine the age-related changes in the vitreous humor by diffusion-weighted imaging (DWI). ( Sakarya Med J 2019, 9(2):266-271).

Materials Between October 2018 and January 2019, patients who underwent brain DWI were retrospectively screened with keyword search in our database and patients with vitreous hemorrhage,

and Methods glaucoma, uncontrolled hypertension and diabetes mellitus were not included to study. In conclusion, 211 patients were included to the study and the patients were divided to decades according to their age. Regression analyses was performed between apparent diffusion coefficient $(A D C)$ values of vitreus humor and age.

Results The mean age of 211 patients (102 female, 109 male) included in the study was 53,8 $( \pm 21,4)$ years, at least 3 years and maximum 89 years. Vitreous humor ADC values increased linearly with increasing age and there was a statistically significant positive correlation $(p<0,001)$. When the ADC values of the vitreous humor were compared between the decades, no significant difference was found between the first and the third decade $(p>0,005)$ and statistically significant difference was found between the other groups $(p<0,005)$.

Conclusion Understanding the structural changes of vitreous humor with aging is important to develop more effective treatment. According to the results of our study, vitreous humor ADC values did not show a significant difference in the first three decades, but showed a positive correlation with age.

Keywords eye; diffusion-weighted imaging; vitreous humor
} 


\section{GIIRIŞ}

Vitreus, sıvı ile çevrili, gevşek ve hassas filamentlerden oluşan, gözün yaklaşık \%80 hacmini kaplayan, lens ile retina arasındaki saydam bölümdür. Tip 2 kollajen, hyaluronik asit ve \%99 sudan oluşan viskoelastik yapıdadır. ${ }^{1}$ Vitreus, lens ve retinayı darbelere karşı korumada mekanik bariyer görevi görmektedir ve gelişim sürecinde gözün büyümesine katkıda bulunmaktadır. ${ }^{2}$

Vitreus humorde, artan yaşa bağlı kollajen fibril ağındaki kırılmalar nedeniyle likefaksiyon artışı ile sonuçlanan de-

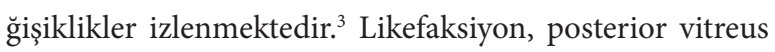
dekolmanı ile sonuçlanan bir sürecin bir etkeni olduğundan, klinik olarak önemli bir durumdur., ${ }^{4,5}$ Ayrıca bu yapısal değişiklikler makroskopik teknikler ile de gözlenebilmektedir. ${ }^{6}$

Difüzyon ağırlıklı görüntüleme (DAG) bir manyetik rezonans görüntüleme (MRG) tekniği olup su moleküllerinin rastgele mikroskobik hareketi özelliklerine dayanır. Difüzyonun miktarı, komşu çevreden ve bu çevredeki anatomik, fizyolojik yapılardan etkilenmektedir. Ayrıca, difüzyon miktarı ile dokunun hücresel yoğunluğu arasında ters ilişki mevcuttur. Bunun sonucunda hücre yoğunluğunun arttığ1 durumlarda difüzyon kısıtlanır ve DAG'da yüksek sinyal elde edilirken, hücresel yoğunluğun azaldığı durumlarda difüzyon artar ve DAG'da düşük sinyal oluşur. ${ }^{7,8}$ Görünür difüzyon katsayısı (ADC) değerleri, difüzyon MRG'de ADC haritalarından region of interest (ROI) kullanılarak kantitatif değer olarak elde edilmektedir. Vitreus humorde yaşlanma ile mikroyapı değiştiğinden bu değişiklikler DAG ile değerlendirilebilmektedir.

Bu çalışmada, vitreus humorde yaşa bağlı ADC değerlerindeki değişiklikleri belirlemeyi amaçladık.

\section{GEREÇ ve YÖNTEMLER}

Çalışmamız kesitsel tipte tanımlayıcı araştırma olup, Erzincan Binali Yıldırım Üniversitesi Klinik Araştırmalar Etik Kurulu'ndan onay alınmıştır (Etik kurul No:2019/38).
Ekim 2018 ile Ocak 2019 tarihleri arasında, Picture Archiving and Communication Systems (PACS) veri tabanında DAG ve beyin anahtar kelimeleri ile beyin DAG MRG tetkiki uygulanan hastalar retrospektif olarak tarandı. Her hastanın demografik özellikleri, tıbbi öyküsü kaydedildi ve kliniğinde vitreus kanaması, glokom, kontrolsüz hipertansiyon veya diabetes mellitusu olan hastalar çalışmaya dahil edilmedi. Sonuçta, beyin MRG ve difüzyon MRG bulguları normal olan 211 hasta çalışmaya dahil edildi ve hastalar yaşlarına göre dekadlara ayrıldı.

Tüm hastalar 1.5 T MRG ünitesi (Magnetom Aera, Siemens Healthcare, Erlangen, Germany) ile standart baş-boyun koili ile değerlendirildi. İntravenöz kontrast madde uygulanan hastalarda DAG kontrast madde verilmeden önce elde edildi. DAG aksiyel 2D spin-eko ve eko-planar görüntüleme (EPI) sekansı kullanıllanılarak elde edildi. Üç ortogonal planda b değerleri 50, 400 ve $1.000 \mathrm{~s} / \mathrm{mm} 2$ olan difüzyon gradyanları kullanıldı. ADC haritaları, sistem tarafından otomatik olarak 50 ve 1.000 b değerleri olan görüntülerden oluşturulmuştur. DAG, belirtilen parametrelerle elde olunmuştur: TR/TE, 3469/92 ms; flip angle, 90; FOV, 230x230 mm; matrix boyutu, 128x90 mm ve kesit kalınlığı 5 mm olarak alınmıştır. ADC değerlerinin ölçülmesi için görüntüler Syngo (Siemens Medical Solutions) iş istasyonuna transfer edildi. Hastaların değerlendirilmesi ve ADC değerlerinin ölçülmesi iki radyoloğun ortak kararı ile yapıldı. Sağ ve sol orbitada vitreus humor üzerine ROI yerleştirilerek ADC değerleri elde edildi.

Tüm veriler SPSS 13.0 (SPSS Inc., Chicago, IL, USA) ve MedCalc istatistiksel yazılım programı versiyon 16.8 (MedCalc Software bvba, Ostend, Belgium) kullanılarak analiz edildi. Sağlıklı 211 olgunun verileri kullanılarak, dekadlara göre vitreus humor ADC değerlerinin minimum, maksimum, ortanca değerleri ve standart sapmaları hesapland. Her dekadda bulunan vaka sayısı ve frekansı hesaplandı. Verilerin normal dağılıma uygunluğu Kolmogorov-Smirnov testi ile değerlendirildi. Sağ ve sol orbita vitreus humor ADC değerleri paired T testi ile karşılaştırıldı. Nor- 
mal dağılım göstermeyen veriler Pearson korelasyon testi ile analiz edilerek R katsayıları ve p değerleri hesaplandi. İstatistiksel olarak p değeri 0,05'den küçük anlamlı olarak kabul edildi. Yaş ile vitreus ADC değerleri arasında regresyon analizi yapılarak regresyon katsayısı hesaplandı ve regresyon denklemi çıkarıldı. Dekadlar arasındaki vitreus humor ADC değerler normal dağılım göstermediğinden gruplar Kruskal-Wallis testi ile karşılaştırıldı ve post hoc analizi Conover-Inman testi yapıldı.

\section{BULGULAR}

Çalışmamızda, 211 hastanın 102 (\%48.3) tanesi kadın ve 109 (\%51.7) tanesi erkek olup ortalaması 53,8 $( \pm 21,4)$ yıl olup en az 3 yil ve en fazla 89 yıldır. Toplam 211 olgunun dekadlara göre, vitreus humor ADC değerleri artış göstermektedir (Tablo 1, Şekil 1). Sağ ve sol orbita vitreus humor ortalama ADC değerleri sırasıyla $3521 \mathrm{~mm} 2 / \mathrm{s}$ ve 3528 $\mathrm{mm} 2 / \mathrm{s}$ olup sağ ve sol orbita vitreus humor ADC değerleri arasında istatistiksel olarak anlamlı fark saptanmadı $(\mathrm{p}=0,425)$.

\begin{tabular}{|l|c|c|c|c|c|}
\hline \multicolumn{1}{|l|}{ Tablo 1. Yaş gruplarına göre olguların ADC değerleri } \\
\hline Yaş (y1) & Say1 & Frekans(\%) & Ortanca (mm2/s) & Minimum (mm2/s) & Maksimum (mm2/s) \\
\hline $0-10$ & 6 & 2,8 & 3099 & 3011 & 3259 \\
\hline $11-20$ & 12 & 5,7 & 3187 & 3068 & 3445 \\
\hline $21-30$ & 18 & 8,5 & 3245 & 3044 & 3567 \\
\hline $31-40$ & 25 & 11,8 & 3350 & 3106 & 3480 \\
\hline $41-50$ & 17 & 8,1 & 3466 & 3334 & 3633 \\
\hline $51-60$ & 35 & 16,6 & 3544 & 3355 & 3685 \\
\hline $61-70$ & 44 & 20,9 & 3653 & 3421 & 3845 \\
\hline $70-79$ & 39 & 18,5 & 3710 & 3498 & 3878 \\
\hline $80-89$ & 15 & 7,1 & 3780 & 3674 & 3961 \\
\hline Toplam & 211 & 100,0 & 3567 & 3011 & 3961 \\
\hline ADC: Görünür difüzyon katsayıs1 & & & & \\
\hline
\end{tabular}

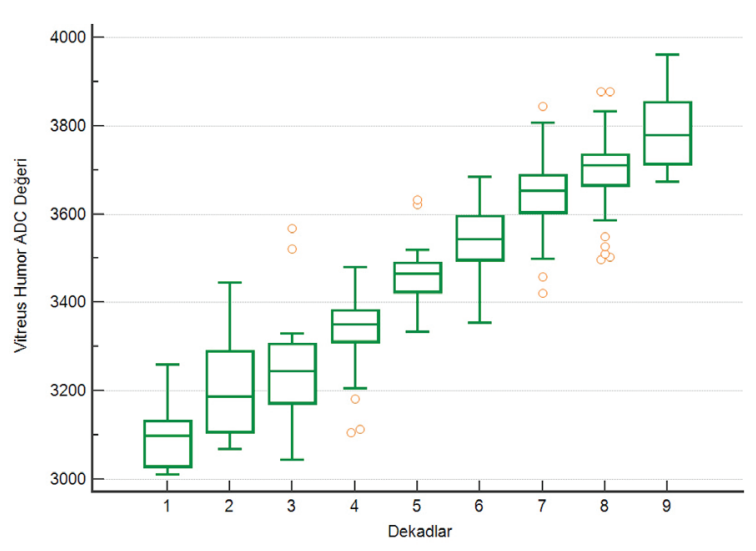

Şekil 1. Dekadlara göre elde edilen vitreus humor ADC değerlerinin kutu-çizgi grafiği

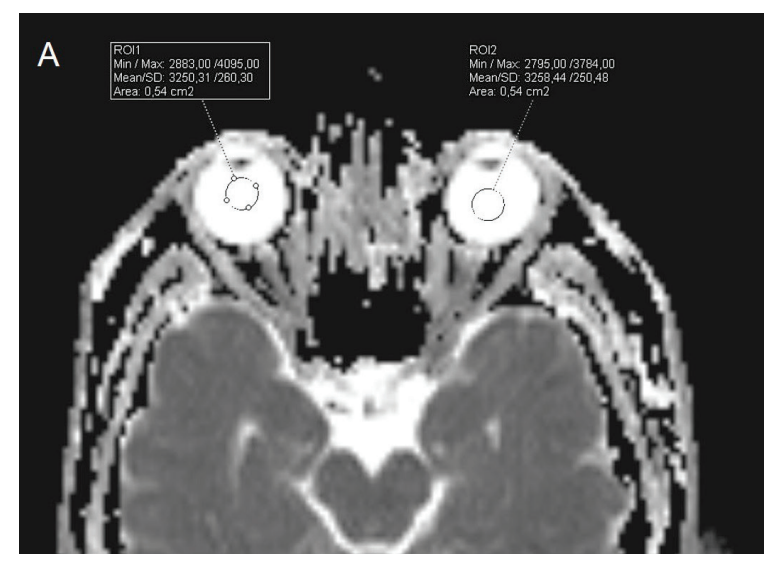

Şekil 2A. 24 yaşında bir olgunun vitreus humorden elde edilen ADC değerleri 


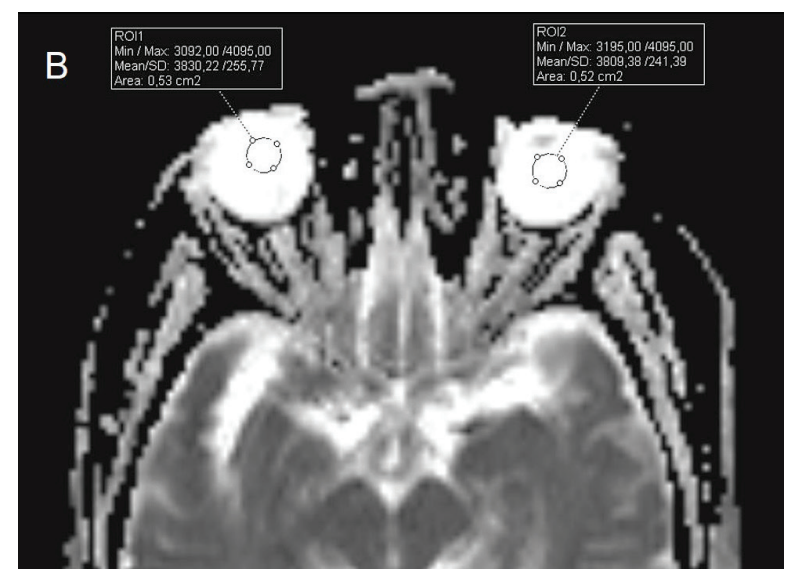

Şekil 2B. 76 yaşındaki bir olgunun vitreus humorden elde edilen ADC değerleri

Olgularda, vitreus humor ADC değerleri, ilerleyen yaş ile birlikte lineer artış göstermektedir (Şekil 2). Vitreus humor ADC değerleri ile yaş arasında istatistiksel olarak anlamlı pozitif korelasyon saptand $1(\mathrm{p}<0,001)$. Vitreus humor $\mathrm{ADC}$ değerleri ile yaş arasındaki ilişkinin regresyon analizi yapıldığında regresyon denklemi vitreus humor ADC değeri=3049,412 +8,841 x yaş, $r=0,932, r 2=0,863$ olarak bulundu (Şekil 3). Dekadlar arasındaki vitreus humor ADC değerleri karşılaştırıldı̆̆ında ilk üç dekad arasında anlamlı fark saptanmazken ( $p>0,005)$ diğer dekadlar arasında istatistiksel anlamlı fark saptand $1(\mathrm{p}<0,005)$.

\section{TARTIŞMA}

$\mathrm{Bu}$ retrospektif çalışmada, vitreus humor ADC değerleri artan yaş ile birlikte lineer artış göstermiştir. Ayrıca, vitreus humor ADC değerleri ile yaş arasında pozitif anlamlı korelasyon saptand.

Gözdeki vitreus humor, sudan zengin bir komponent olup çeşitli tuzlar, çözünmüş protein, kollajen ve hyalüronik asit gibi ekstraselüler matris bileşenleri içeren şeffaf bir jelden oluşmaktadır. ${ }^{9}$ Vitreus humorun jelatinöz durumu, uzun ince kollajen fibril ağı tarafından korunur. ${ }^{10}$ Bebeklik döneminde likefaksiyon göstermeyen, oldukça homojen yapıda olan vitreus humor zamanla yaşa bağlı değişiklikler göstermektedir. ${ }^{11}$ Yaşlılık süresince özellikle merkezdeki fibriller birleşerek fiberlere dönüşür ve bunun sonucunda fibriller arasındaki hyalüronik asit bağlantılarının çözüne-

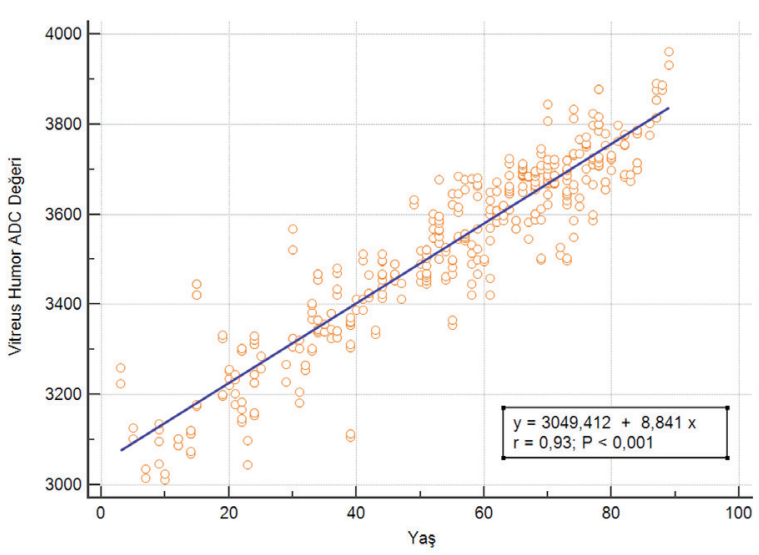

Şekil 3. Yaş ile vitreus humor ADC değerleri arasındaki Pearson lineer regresyon grafiği

rek sıvı poşları oluşmasına neden olur. Likefiye olan vitreus humorde kollajen yapıları azalmaktadır. Morfolojik olarak, likefiye alanların hacminde (senkriz) ve optik olarak zayıflatılmış alanlarda artış var (sineresis) izlenmektedir. $^{12-14}$

Difüzyon, su moleküllerinin termal enerjiye bağlı olarak rasgele hareketi olup ADC ile kantitatif olarak değerlendirilebilmektedir. ${ }^{15}$ DAG ile hücre membranlarının permeabilitesindeki değişiklikler, hücre lizisi gibi su içeriğindeki değişiklikler, dokuların morfolojik ve fizyolojik değişiklik değerlendirilebilmektedir. ${ }^{16}$ Ayrıca, difüzyon değerleri, hücre miktarının değiştiği durumlarda hücre dışındaki su moleküllerinin hareket hızı etkilendiğinden hücreselliğin değerlendirilebilmesine olanak sağlar. ${ }^{16}$

DAG ile ayrıca dokulardaki mikrositrüktürel yapı da değerlendirilebilmektedir, bu sayede yaşlanmaya bağlı değişikliklerde DAG ile saptanabilmektedir. Yaşlanma ile beyin gri ve beyaz cevherde olan değişiklikler DAG ile değerlendirildiğinde yaşa bağlı olarak ADC değerlerinde artış bildirilmiştir. ${ }^{17,18} \mathrm{Biz}$ de çalışmamızda, vitreus humorde oluşan yaşlanma ile ilişkili değişikliklerin DAG ile saptanabileceğini düşündük.

Çalışmamızın sonuçlarına göre, vitreus humor ADC değerleri artan yaş ile birlikte pozitif lineer artış göstermiştir. Ayrıca, vitreus humor ADC değerleri ile yaş arasında 
istatistiksel olarak anlamlı pozitif korelasyon mevcuttu. Dekadlar arasındaki ADC değerleri karşılaştırıldı̆̆ında ilk üç dekad arasında anlamlı fark saptanmazken diğer dekadlarda istatistiksel olarak anlamlı şekilde ortanca ADC değerlerinde artış saptandı. Meral ve ark. yaptığı çalışmalarında vitreus humor ADC değerlerinin yaşlanma ile birlikte arttığını bildirmişlerdir. ${ }^{19}$ Yaşlanma ile vitreus humorde oluşan likefaksiyon ile fibril oranında azalma ile sıvının artmış hareketine bağlı olarak ADC değerlerinde artış olduğu düşünülmektedir.

Doğum sonrası gözün iç kısmının büyük bir kısmı optik olarak şeffaf olan vitröz humor ile doludur. ${ }^{20}$ Vitröz humorün yaşlanmayla devam eden likefaksiyon süreci ilk dekaddan sonra başlamaktadır. İleri yaşlarda ise vitreal kaviteyi belirgin azalan jel kıvamındaki içerik yerine su benzeri likefiye olmuş sıvı içerik doldurmaktadır. ${ }^{20}$ İlerleyen yaşla birlikte likefiye olan vitreus humor sonucunda gözün oksidatif stresden korunma mekanizmalarından biri kaybedilmiş olunmaktadır. ${ }^{21}$ Bozulmuş oksidatif stres mekanizması, katarak, açık açılı glokom ve retinal hastalıklara neden olmaktadır. ${ }^{22,23}$ DAG, endoftalmi, orbital seliliüt, orbital abse, retinal dekolman ve retinal tümörlerin değerlendirilmesinde klinik olarak kullanılmaktadır ${ }^{24}$. Bu nedenle sağlıklı popülasyondaki ADC değerlerinin ölçümü ve normal değerlerin bilinmesi patolojik durumların ayırt edilmesine yardımcı olabilir.

Çalışmamızın başlıca kısıtlılıkları, kullanıcı içi ve kullanıcılar arası değişkenliği değerlendirememiş olmamız, hasta sayısının yeterli olmaması ve DAG ile edilen ADC değerlerinin belirlenen parametrelere göre MR cihazları arasında farklılık göstermesidir.

Vitreus humorde, yaşlanmayla beraber oluşan yapısal değişikliklerin anlaşılması daha etkili tedavi geliştirmek için önemlidir. Çalışmamızın sonuçlarına göre, vitreus humor ADC değerleri ilk üç dekadda anlamlı fark göstermemekle beraber ilerleyen dekadlarda pozitif korelasyon gösterdi. DAG’nin vitreus humordeki değişiklerini belirlemede daha geniş olgu gruplarını içeren çalışmalara ihtiyaç vardir.

\section{Maddi Destek ve Çıkar İlişkisi}

Çalışmayı maddi olarak destekleyen kişi veya kuruluş yoktur. Ayrıca yazarların herhangi bir çıkara dayalı ilişkisi de yoktur. 
Sakarya Tip Dergisi 2019;9(2):266-271

KÜPELİ ve Ark. Yaş ve Vitreus Humor Difüzyon MRG Özelikleri

Kaynaklar

1. Le Goff MM, Bishop PN. Adult vitreous structure and postnatal changes. Eye 2008;22: $1214-1222$.

2. COULOMBRE AJ. The role of intraocular pressure in the development of the chick eye. I. Control of eye size. J. Exper. Zool 1956;133:211-225.

3. Los LI, van der Worp RJ, van Luyn MJ, Hooymans JM. Age-related liquefaction of the human vitreous body: LM and TEM evaluation of the role of proteoglycans and collagen. Invest Ophthalmol Vis Sci 2003;44:2828-2833.

4. Foos RY, Wheeler NC. Vitreoretinal juncture: synchysis senilis and posterior vitreous detachment. Ophthalmology 1982;89:1502-1512.

5. Foos RY. Posterior vitreous detachment. Trans Am Acad Ophthalmol Otolaryngol 1972;76:480-496.

6. Eisner G. [Postmortem slitlamp study of the vitreous body. 3. Relation to histology, biomicroscopy and clinical applications]. Albrecht Von Graefes Arch Klin Exp Ophthalmol 1971;182:23-40.

7. Deike-Hofmann K, Kuder T, König F, Paech D, Dreher C, Delorme S, et al. Diffusion-weighted breast imaging. Radiologe. 2018;58:14-19.

8. de Figueiredo EH, Borgonovi AF, Doring TM. Basic concepts of MR imaging, diffusion MR imaging and diffusion tensor imaging. Magn Reson Imaging Clin N Am 2011;19:1-22.

9. Zhu ZR, Goodnight R, Sorgente N, Ogden TE, Ryan SJ. Morphologic observations of retinal pigment epithelial proliferation and neovascularization in the rabbit. Retina 1989;9:319327

10. Itakura H, Kishi S, Kotajima N, Murakami M. Decreased vitreal hyaluronan levels with agingi Ophthalmologica 2009;223:32-35

11. Bishop PN. Structural macromolecules and supramolecular organisation of the vitreous gel. Prog Retin Eye Res 2000;19:323-344.

12. Böhm MRR, Thomasen H, Parnitzke F, Steuhl KP. [Clinical, morphological and molecular biological characteristics of the aging eye]. Ophthalmologe 2017;114:98-107.

13. Eisner G. Postmortem slitlamp study of the vitreous body. II. Pattern of vitreous structures made visible by the slitbeam. Albrecht Von Graefes Arch Klin Exp Ophthalmol 1971;182:8-

\section{2}

14. Sebag J. Age-related changes in human vitreous structure. Graefes Arch Clin Exp Ophthalmol 1987;225:89-93

15. Basser PJ, Mattiello J, Le Bihan D. Estimation of the effective self diffusion tensor from the NMR spin echo. J Magn Reson B 1994;103:247-254.

16. Seiko Kuroki-Suzuki, Yoshifumi Kuroki, Katsuhiro Nasu, Shigeru Nawano, Noriyuki Moriyama, Masatoshi Okazaki. Detecting Breast Cancer with Non-contrast MR Imaging: Combining Diffusion-weighted and STIR Imaging. Magn Reson Med Sci 2007;6:21-27.

17. Lövblad KO, Delavelle J, Wetzel S, Kelekis AD, Assal F, Palmesino M, et al. ADC mapping of the aging frontal lobes in mild cognitive impairment. Neuroradiology 2004;46:282-286.

18. Engelter ST, Provenzale JM, Petrella JR, DeLong DM, MacFall JR. The effect of aging on the apparent diffusion coefficient of normal-appearing white matter. AJR Am J Roentgenol 2000; 175:425-430

19. Meral I, Bilgili Y. Diffusion changes in the vitreous humor of the eye during aging. AJNR Am J Neuroradiol 2011;32:1563-6.

20. Sebag J. The vitreous. In: Adler FH, Hart WM, eds. Adler's physiology of the eye. 9th ed. St. Louis: Mosby 1992:268-347.

21. Shui YB, Holekamp NM, Kramer BC, Crowley JR, Wilkins MA, Chu F, et al. The gel state of the vitreous and ascorbate-dependent oxygen consumption: relationship to the etiology of nuclear cataract. Arch Ophthalmol 2009;127:475-482.

22. Chang S. LXII Edward Jackson lecture: open angle glaucoma after vitrectomy. Am J Ophthalmol 2006; 141:1033-1043.

23. Sebag J. Anomalous posterior vitreous detachment: a unifying concept in vitreo-retinal disease Graefes Arch Clin Exp Ophthalmol. 2004;242:690-698.

24. Paul K, Graessl A, Rieger J, Lysiak D, Huelnhagen T, Winter L, et al. Diffusion-sensitized ophthalmic magnetic resonance imaging free of geometric distortion at 3.0 and 7.0 T: a feasibility study in healthy subjects and patients with intraocular masses. Invest Radiol 2015;50:309-321. 